Research Article

\title{
Permeability of Concrete and Correlation with Microstructure Parameters Determined by ${ }^{1} \mathrm{H}$ NMR
}

\author{
Yurong Zhang, ${ }^{1}$ Shengxuan Xu, ${ }^{1}$ Zhaofeng Fang, ${ }^{1}$ Junzhi Zhang $\mathbb{D},{ }^{1,2}$ and Chaojun Mao ${ }^{1}$ \\ ${ }^{1}$ College of Civil Engineering and Architecture, Zhejiang University of Technology, Hangzhou 310014, China \\ ${ }^{2}$ Key Laboratory of Civil Engineering Structure \& Disaster Prevention and Mitigation Technology of Zhejiang Province, \\ Hangzhou 310014, China
}

Correspondence should be addressed to Junzhi Zhang; jzzhang@zjut.edu.cn

Received 30 August 2019; Revised 7 April 2020; Accepted 20 April 2020; Published 14 May 2020

Academic Editor: Luís Evangelista

Copyright (C) 2020 Yurong Zhang et al. This is an open access article distributed under the Creative Commons Attribution License, which permits unrestricted use, distribution, and reproduction in any medium, provided the original work is properly cited.

Water and gas permeability coefficients of concrete with different water-binder (w/b) ratios and admixtures were measured by a self-designed test device based on the steady-state flow method for liquid and the method of differential pressure in stability for gas, respectively. In addition, the micropore structure of concrete was determined by ${ }^{1} \mathrm{H}$ nuclear magnetic resonance (NMR). Results indicated that there are good correlations between water and gas permeability of concrete with different w/b ratios, with correlation coefficient greater than 0.90 . Better correlations between water permeability and segmental contributive porosity ranged from 10 to $100 \mathrm{~nm}$ and 100 to $1000 \mathrm{~nm}$ can be identified, but the gas permeability is more relevant to the segmental contributive porosity ranging from 100 to $1000 \mathrm{~nm}$. Moreover, the correlation between water permeability and contributive porosity for each pore diameter is always better than that of gas permeability. The influence of admixtures on the relationship between permeability and pore size distribution of concrete is significant. Moreover, water permeability coefficient is one or two orders of magnitude lower than the gas permeability coefficient.

\section{Introduction}

Water and gas permeability are considered reliable indicators to evaluate the durability of concrete [1]. For most liquids, the flow rate is proportional to the pressure gradient and independent of the fluid used. Unlike water permeability, gas permeability is dependent on the nature of gas and shows a linear function of the reciprocal mean pressure, which can be called Klinkenberg effect or the theory of gas slippage [2]. Since water contains gas and liquid states, the water permeability in concrete should include the contributions of these two states mentioned above [3]. For concrete with low porosity and high compactness, it is inappropriate to test water permeability of concrete by the water pressure method $[4,5]$. Anez et al. proposed an approximated linear relationship between gas permeability, water permeability, reciprocal mean pressure, and Klinkenberg factor [6]. Previous research indicated that water permeability coefficient was $1 \sim 2$ orders of magnitude lower than gas permeability coefficient [7]. Kameche et al. [8] suggested that the significant difference between water and gas permeability coefficients of concrete may be attributed to different pretreatment methods of specimens. Skoczylas and Henry [9] found that when pure water is injected into the pores of concrete, the chemical equilibrium of various phases presented in concrete will be disrupted, leading to a dissolution or precipitation phenomena of microcomponents in concrete. Marchand [10] indicated that the effective pore diameter is progressively reduced with water penetration into sample due to the expansion of cementbased materials caused by the capillary adsorption of water. It is worth noting that, to determine the water permeability coefficient of concrete, an accurate and reproducible measurement becomes tedious and difficult [11], and the internal water saturation will have a greater impact on the test results [12]. Therefore, the focus has been shifted to gas permeability, which is easier to measure, requires less time, and produces more reproducible results [13]. If an effective 
mutual relationship between water and gas permeability of concrete can be determined, a rapid and easy estimation on water permeability coefficient can be obtained.

It is well known that there is a good correlation between the microstructure parameters of concrete and its permeability [14]. Chen et al. [15] used limestone powder as a cement substitute to evaluate the water resistance of concrete and found a significant linear correlation between permeable porosity and water penetration depth, as well as sorptivity coefficient. Yan et al. [16] investigated the relationship between transfer properties and porosity of a normalized mortar heated up to $600^{\circ} \mathrm{C}$. Sinsiri et al. [17] indicated that gas permeability of cement-based materials with fly ash decreased with porosity. By investigating the effects of clinker and limestone quality on gas permeability, water absorption, and pore structure, Tsivilis et al. [18] ascertained that the pore size distribution, especially the mean pore size, affects the gas permeability and water absorption of concrete. At present, numerous techniques have been employed to investigate the microstructure of concrete, including nitrogen adsorption, gravimetry, X-ray computed tomography (X-CT), mercury intrusion porosimetry (MIP), and ${ }^{1} \mathrm{H}$ nuclear magnetic resonance (NMR). The sample size of the MIP test is small, which is difficult to reflect the real situation of concrete. In addition, the high-pressure intrusion by mercury and pore shielding effect may either deform or destroy the sample, leading to inaccurate results [19]. NMR is one of the most effective probes to obtain the microstructure parameters closer to the real situation, with the noninvasive and nondestructive properties. Ji et al. [20] evidenced that the peaks of transverse relaxation time distribution correlate with the microstructure of fresh cement paste based on ${ }^{1} \mathrm{H}$ low-field NMR. Zhang et al. [21] measured pore characteristic parameters and pore-size distribution with exposure time by NMR technology. Tziotziou et al. [22] applied ${ }^{1} \mathrm{H}$ nuclear magnetic resonance relaxation to monitor the hydration and porosity evolution of limepozzolan mixtures during its setting in real time. Zhou et al. [23] investigated the pore structure of white cement mortars during water vapor adsorption kinetics by the NMR technique. Thus, it can be seen that the NMR method has been increasingly used to characterize the microstructure parameters of concrete in recent years. However, research on the relationship between water as well as gas permeability and porosity measured by NMR is still rare.

To investigate the correlation between water and gas permeability of concrete, test concrete mixture proportions with different water-binder $(\mathrm{w} / \mathrm{b})$ ratios and mixtures were designed. Firstly, water and gas permeability coefficients of the test concrete were measured with a self-designed test device based on the method of differential pressure in stability for gas [24] and the steady-state flow method for liquid. The microstructure parameters such as porosity and pore size distribution of the test concrete were tested by NMR. Secondly, based on the test results, the influences of $\mathrm{w} / \mathrm{b}$ ratio and admixtures on water and gas permeability of concrete were explored. Moreover, the correlation between water and gas permeability was analyzed. Further, the reasons and influence factors causing a difference between water and gas permeability coefficients were attempted to be identified, and the influences of $\mathrm{w} / \mathrm{b}$ ratio and admixture on the microstructure parameters of concrete and its macropermeability were discussed. At last, the degree of correlation between water and gas permeability and segmental contributive porosity with different pore diameters was analyzed.

\section{Materials and Proportions of Concrete}

River sand with an apparent density of $2600 \mathrm{~kg} / \mathrm{m}^{3}$ and modulus of fineness of 2.5 were used as fine aggregate. Coarse aggregate with an apparent density of $2700 \mathrm{~kg} / \mathrm{m}^{3}$ was gravel with a maximum particle size of $40 \mathrm{~mm}$ and a continuous grading range of $5 \sim 40 \mathrm{~mm}$. The weight of tap water for mixing was $190 \mathrm{~kg} / \mathrm{m}^{3}$. Portland cement P.C 32.5 was used, with detailed properties shown in Table 1.

Since fly ash (FA) and silica fume (SF) are the widely used admixtures, and basalt fiber (BF) is gaining extensive attentions recently, therefore, these three types of admixture are chosen to investigate their effect on the permeability and microstructural properties of concrete. The chemical compositions of used cement and admixtures are listed in Table 2.

Nine concrete mixtures (Table 3) were designed to investigate the influences of $\mathrm{w} / \mathrm{b}$ ratio and admixture on water and gas permeability of concrete.

\section{Experimental Procedure and Methods}

3.1. Specimens Casting. According to the concrete mixtures mentioned in Table 3, for each mix proportion, two rectangular concrete specimens $(150 \mathrm{~mm} \times 150 \mathrm{~mm} \times 550 \mathrm{~mm})$ were produced. All specimens were cured in accordance with test code for hydraulic concrete (SL352-2006). After 28 days of curing, each rectangular specimen was cut into six pieces with size of $150 \mathrm{~mm} \times 150 \mathrm{~mm} \times 50 \mathrm{~mm}$. Three were used to measure water permeability and the other three were used to measure gas permeability. Figure 1 shows the schematic diagram of cutting concrete samples.

In addition, for each mix proportion, three cubic specimens with side length of $150 \mathrm{~mm}$ were cast simultaneously and cured in the standard curing room. Then, the $28 \mathrm{~d}$ compressive strength of cubic concrete specimens was measured, as shown in Table 3.

3.2. Test Method for Permeability. It is well known that, for concrete with lower porosity, its pore size is in a micrometer or nanometer scale. Moreover, the pores with higher tortuosity and lower connectivity may lead to lower water and gas permeability of concrete. In general, the water permeability of concrete ranges from $10^{-19} \mathrm{~m}^{2}$ to $10^{-17} \mathrm{~m}^{2}$, while the gas permeability is higher than that of water permeability at least one or two orders of magnitude [7, 8].

It is time-consuming to infiltrate water or gas from one side of cement-based specimen to the other side, since the seepage flow is very small. Moreover, it is difficult to accurately measure the seepage flow volume in a unit time. Therefore, an experimental device which can measure water 
TABle 1: Physical and mechanical properties of cement.

\begin{tabular}{|c|c|c|c|c|c|c|c|c|c|}
\hline $\begin{array}{l}\text { Standard } \\
\text { consistency (\%) }\end{array}$ & $\begin{array}{c}\text { Fineness } \\
(\%)\end{array}$ & $\begin{array}{c}\text { Density } \\
\left(\mathrm{g} / \mathrm{m}^{3}\right)\end{array}$ & \multicolumn{2}{|c|}{ Setting time $(\mathrm{min})$} & \multicolumn{2}{|c|}{$\begin{array}{c}\text { Flexural } \\
\text { strength } \\
(\mathrm{MPa})\end{array}$} & \multicolumn{2}{|c|}{$\begin{array}{c}\text { Compressive } \\
\text { strength } \\
(\mathrm{MPa})\end{array}$} & Stability \\
\hline \multirow[t]{2}{*}{29.0} & \multirow[t]{2}{*}{5.6} & \multirow[t]{2}{*}{3.02} & \multirow{2}{*}{$\begin{array}{c}\text { Initial } \\
\text { setting } \\
250\end{array}$} & \multirow{2}{*}{$\begin{array}{c}\text { Final } \\
\text { setting } \\
320\end{array}$} & $3 \mathrm{~d}$ & $28 \mathrm{~d}$ & $3 \mathrm{~d}$ & $28 \mathrm{~d}$ & \multirow[t]{2}{*}{ Qualification } \\
\hline & & & & & 4.12 & 5.68 & 20.4 & 51.3 & \\
\hline
\end{tabular}

TABle 2: Chemical compositions of cement and mineral admixtures (\%).

\begin{tabular}{|c|c|c|c|c|c|}
\hline Material & $\mathrm{SiO}_{2}$ & $\mathrm{Al}_{2} \mathrm{O}_{3}$ & $\mathrm{Fe}_{2} \mathrm{O}_{3}$ & $\mathrm{CaO}$ & $\mathrm{MgO}$ \\
\hline Cement & 24.55 & 10.48 & 2.16 & 51.16 & 6.01 \\
\hline Fly ash & 47.66 & 20.81 & 9.84 & 11.51 & 1.51 \\
\hline Silica fume & 98.02 & 0.42 & 0.09 & 0.29 & 0.41 \\
\hline Basalt fiber & 54.00 & 16.50 & 11.50 & 7.00 & 4.50 \\
\hline
\end{tabular}

TABLE 3: Concrete mixture proportions ${ }^{\mathrm{f}}$.

\begin{tabular}{|c|c|c|c|c|c|c|c|c|}
\hline \multirow{3}{*}{ Number } & \multicolumn{6}{|c|}{ Content $\left(\mathrm{kg} / \mathrm{m}^{3}\right)$} & \multirow{3}{*}{$\mathrm{W} / \mathrm{B}$} & \multirow{3}{*}{$28 \mathrm{~d}$ compressive strength $(\mathrm{MPa})$} \\
\hline & \multirow{2}{*}{$\mathrm{C}$} & \multirow{2}{*}{ FA } & \multirow{2}{*}{ SF } & \multirow{2}{*}{$\mathrm{BF}$} & \multicolumn{2}{|c|}{ Aggregate $^{\mathrm{e}}$} & & \\
\hline & & & & & $\mathrm{F}$ & $\mathrm{C}$ & & \\
\hline A1 & 475.0 & - & - & - & 552 & 1174 & 0.40 & 35.4 \\
\hline A2 & 422.0 & - & - & - & 567 & 1204 & 0.45 & 29.0 \\
\hline A3 & 380.0 & - & - & - & 578 & 1229 & 0.50 & 25.7 \\
\hline A4 & 346.0 & - & - & - & 589 & 1249 & 0.55 & 21.9 \\
\hline A5 & 317.0 & - & - & - & 597 & 1269 & 0.60 & 16.9 \\
\hline$A 6^{\mathrm{a}}$ & 304.0 & 76 & - & - & 578 & 1229 & 0.50 & 22.2 \\
\hline $\mathrm{A} 7^{\mathrm{b}}$ & 266.0 & 114 & - & - & 578 & 1229 & 0.50 & 21.2 \\
\hline $\mathrm{A} 8^{\mathrm{c}}$ & 361.0 & - & 19 & - & 578 & 1229 & 0.50 & 31.0 \\
\hline$A 9^{d}$ & 380.0 & - & - & 1.03 & 578 & 1229 & 0.50 & 29.3 \\
\hline
\end{tabular}

${ }^{\mathrm{a}} \mathrm{A6}$ : cement replacement FA, $20 \%$ by weight of $380 \mathrm{~kg}$ cement. ${ }^{\mathrm{b}} \mathrm{A} 7$ : cement replacement FA, $30 \%$ by weight of $380 \mathrm{~kg}$ cement. ${ }^{\mathrm{c}} \mathrm{A} 8$ : cement replacement SF, $5 \%$ by weight of $380 \mathrm{~kg}$ cement. ${ }^{\mathrm{d}} \mathrm{A} 9: 0.3 \%$ by volume of cement, which is $1.03 \mathrm{~kg} / \mathrm{m}^{3}$. ${ }^{\mathrm{e}}$ Fine aggregates $(\mathrm{F}): 100 \% \mathrm{~m} / \mathrm{m}$ passing an $8 \mathrm{~mm}$ sieve, $96.5 \% \mathrm{~m} / \mathrm{m}$ passing a $4 \mathrm{~mm}$ sieve. Coarse aggregates (C): $100 \% \mathrm{~m} / \mathrm{m}$ passing a $40 \mathrm{~mm}$ sieve, $40 \% \mathrm{~m} / \mathrm{m}$ passing a $16 \mathrm{~mm}$ sieve. ${ }^{\mathrm{f}} \mathrm{A} 1-\mathrm{A} 7$ in Table 3 is identical to the content in Table 2 of [24], A8 and A9 herein refer to A9 and A10 in Table 2 of [24].

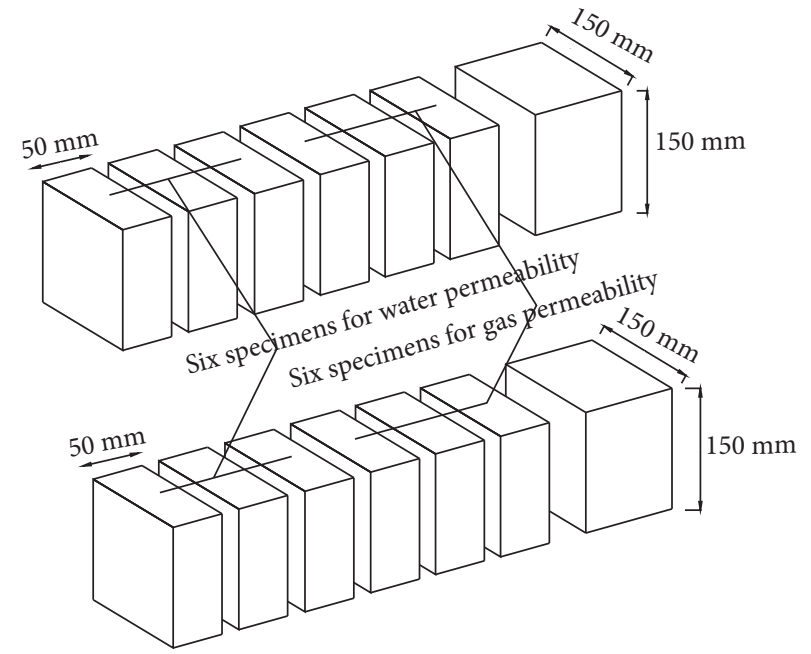

FIGURE 1: Schematic cutting on concrete samples.

and gas permeability coefficients of specimens and reduce test errors was designed in this paper, based on the method of differential pressure in stability for gas $[25,26]$ and the steady-state flow method for liquid [2]. By comparing the experimental measurements with results from other literature, the self-designed device has a relatively simple test method and much higher stability of test results. Figures 2 and 3 show the schematic diagram of the self-designed device and principle for testing permeability of concrete.

To measure water permeability coefficient, the specimens should be put into distilled water for 24 hours under vacuum. Moreover, the specimens were laterally sealed by wax to ensure unidirectional flow of water and avoid side leakage during the permeability test. And then, they were put into the device, located between top cap and clamp plate, as shown in Figure 3, to ensure a square water permeable area of $0.0064 \mathrm{~m}^{2}$ with side of $80 \mathrm{~mm}$, square rubber rings of $5 \mathrm{~mm}$ thickness, $80 \mathrm{~mm}$ inside length, and $135 \mathrm{~mm}$ outside length was placed on upper and lower faces of the specimens. At last, a pressure was applied to the specimen by the H4-S fully automatic permeameter to accelerate the water flow. The pressure increased from $0 \mathrm{MPa}$ to $2 \mathrm{MPa}$ and remained unchanged for 8 hours. Until reaching a stable flow of water, the water flux was measured every four hours. After seepage of water has stabilized, the water quantity flowing through 


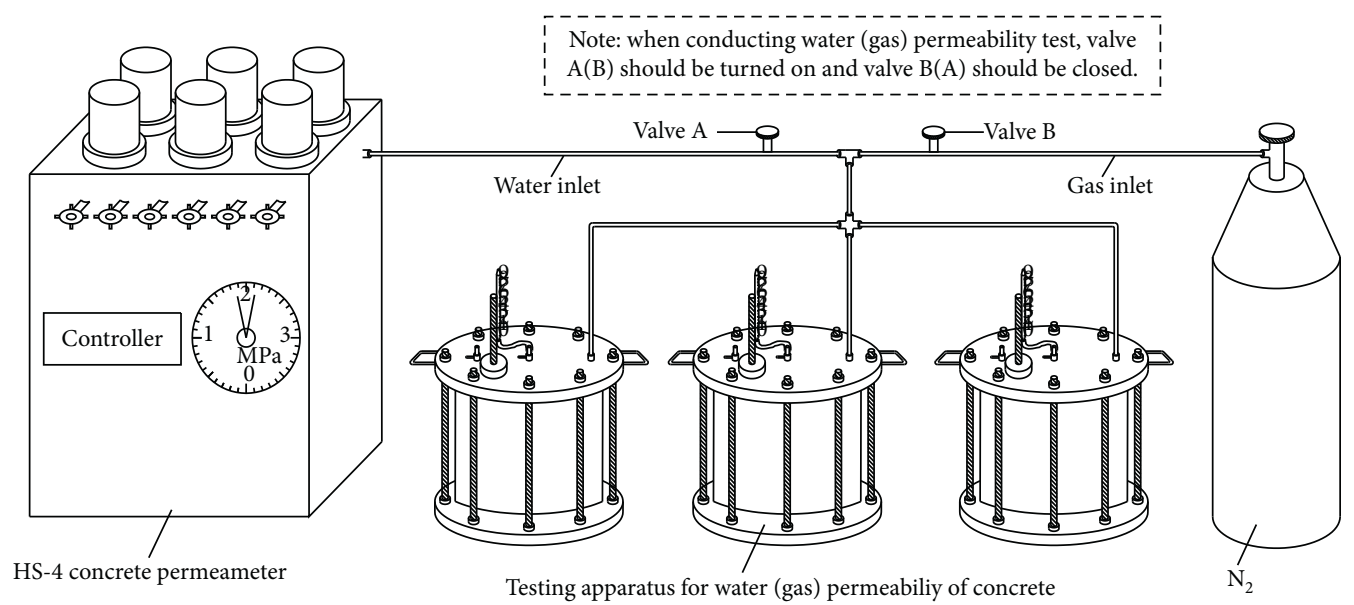

FIGURE 2: Schematic diagram of device for measuring permeability of concrete.

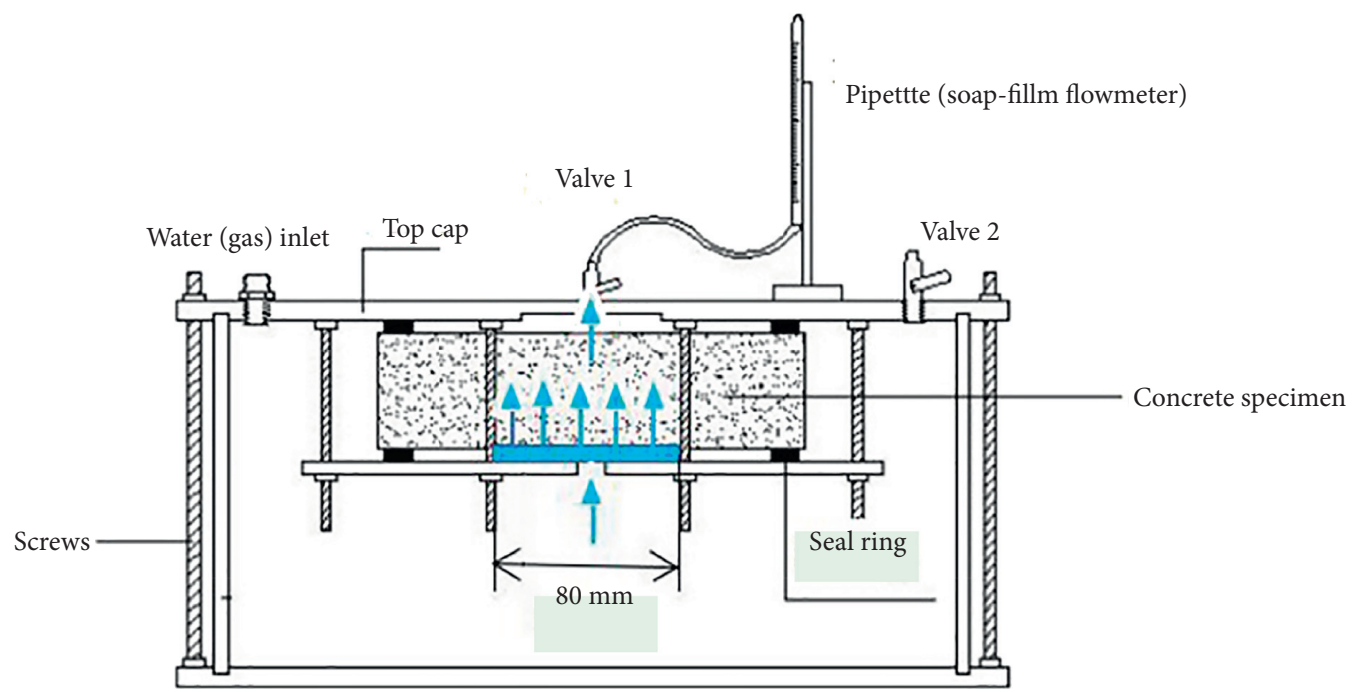

FIgURE 3: Principle for testing permeability of concrete.

concrete specimen was measured by reading the increase of water level in a pipette. The steady-state flow $Q$ was obtained by the average of three recordings after a stable flow. Boundary conditions of water permeability in concrete are shown in Figure 4.

In a steady injection state, the pressure variation in the sample is given by the well-known expression [27]:

$$
P(x)=\sqrt{P_{i}^{2}\left(1-\frac{x}{h}\right)+P_{0}^{2} \frac{x}{h}}
$$

where $P_{i}$ is the injection pressure $(\mathrm{MPa}), P_{0}$ is the draining pressure $(\mathrm{MPa})$, which is maintained at atmospheric level in this case, and $h$ is the length of the specimen $(\mathrm{m})$.

According to the boundary conditions in Figure 4, Darcy's law can be written for a one-dimensional flow [27-29], as shown in

$$
V_{x}=-\frac{K_{x}}{\mu} \frac{\mathrm{d} P}{\mathrm{~d} x}
$$

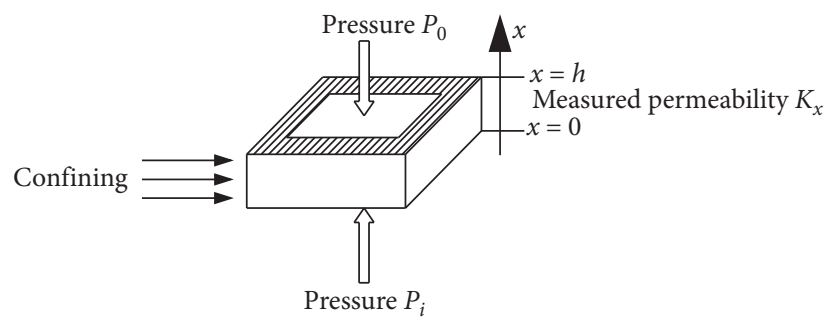

FIgURE 4: Boundary conditions.

where $V_{x}$ is the water or gas velocity $(\mathrm{m} / \mathrm{s})$ and $\mu$ is the viscosity $(\mathrm{Pa} \cdot \mathrm{s})$.

Substituting the boundary condition of water penetration test into equation (2) and the equation for water permeability coefficient can be obtained:

$$
K_{w}=\mu_{w} \frac{Q}{\Delta p} \frac{h}{A},
$$


where $\mu_{w}$ is the dynamic viscosity of water (depending on the temperature of water in the experiment $)\left(10^{-6} \mathrm{kPa} \cdot \mathrm{s}\right), \mathrm{Q}$ is the average flow through the concrete $\left(\mathrm{m}^{3} / \mathrm{s}\right), h$ is the height of the specimen $(\mathrm{m}), A$ is the cross-sectional area of water $\left(\mathrm{m}^{2}\right)$, and $\Delta P$ is the difference value of water pressure between upper and lower surfaces of test samples (MPa).

The procedure of gas permeability test followed the Cembureau method recommended by RILEM, in which $\mathrm{N}_{2}$ of high purity was used as the injection $[25,26]$. As the permeability test is based on the measurement of intrinsic permeability by gas injection, the sample must be dried continuously for $48 \mathrm{~h}$ in an oven, drying at a temperature of $105^{\circ} \mathrm{C} \pm 5^{\circ} \mathrm{C}$ before testing. Then, the samples were weighted when they were cooled to room temperature. The upper surface of the specimen for gas permeability was connected to the atmosphere and the lower surface was subjected to a constant upstream pressure of $0.3 \mathrm{MPa}$ (injection pressure). The volumetric flow rate of the gas was measured when the injection was continued for 30 minutes to ensure that the gas flew stably through the specimen (steady state).

Unlike water, gas is compressible. Therefore, it is necessary to correct the gas permeability coefficient $K_{q}$ based on equation (4), which can be expressed as follows $[8,30]$ :

$$
K_{g}=\frac{h}{A} \mu_{g} \frac{2 Q P_{a}}{\left(P^{2}-P_{a}^{2}\right)}
$$

where $\mu_{g}$ is the dynamic viscosity of $\mathrm{N}_{2}$ (depending on the temperature of $\mathrm{N}_{2}$ in the experiment) (kPa.s), $Q$ is the volumetric flow $\left(\mathrm{m}^{3} / \mathrm{s}\right), h$ is the height of the specimen $(\mathrm{m})$, $A$ is the cross-sectional area of gas $\left(\mathrm{m}^{2}\right), P$ is the injection pressure (MPa), and $P_{a}$ is the atmospheric pressure (MPa).

3.3. NMR to Determine Microscopic Structure of Concrete. MesoMR23-060H-I, produced by Niumag Electric Corporation, Suzhou City, Jiangsu Province, China, was adopted for the ${ }^{1} \mathrm{H}$ NMR test. In this experiment, the NMR test instrument has a $0.5 \mathrm{~T}$ constant magnetic field and a radiofrequency coil of $60 \mathrm{~mm}$ in diameter and is operating at $23.4033 \mathrm{MHz}$ and $32^{\circ} \mathrm{C}$ magnet temperature. Table 4 shows the Carr Purcell Meiboom Gill (CPMG) parameters of transverse relaxation time $\left(T_{2}\right)$ test.

The cubic samples with side length of $40 \mathrm{~mm}$ were used for the NMR test, which were cut down from the rectangular concrete specimens. The specific test steps are as follows.

(1) The dust on the surface of the samples was cleaned with a brush

(2) The samples were immersed into distilled water at the vacuum pressure of $0.1 \mathrm{MPa}$ for 10 hours to ensure that the samples were fully water saturated [31]

(3) The specimens were taken out of the water and the exterior moisture was wiped off and then the specimens were wrapped with preservative films

(4) The specimens were placed in the magnet coil to perform the ${ }^{1} \mathrm{H}$ NMR test

Temperature and magnetic field intensity may have effects on the test results. Therefore, after determining the
CPMG parameters, the relationship between the unit volume nuclear magnetic signal and porosity was standardized based on the standard sample with a predetermined porosity. Then, the same parameters and test steps were used to calibrate the standard sample and obtain the calibration curve. Figure 5 shows the calibration curve.

Based on the hypothesis of fast exchange, when the sample is filled with water, the ratio of the $T_{2}$ value of a single pore to surface-to-volume ratio is well proportional. Thus, the pore distribution can be determined based on the $T_{2}$ spectrum as follows $[32,33]$ :

$$
\frac{1}{T_{2}} \approx \frac{1}{T_{2, \text { sur }}}=\rho_{2} \times\left(\frac{A}{V}\right),
$$

where $T_{2}$ is the relaxation time of water in pore, $T_{2, \text { sur }}$ is the relaxation time of surface, $T_{2}$ is the surface relativity, $A$ is the area of the pore wall, and $V$ is the fluid volume.

\section{Results and Analysis}

4.1. Permeability and Its Influencing Factors. Water and gas permeability coefficient of concrete with different waterbinder ratios and admixtures at the age of $28 \mathrm{~d}$ are shown in Figure 6. It is worth noting that the values of water and gas permeability coefficients are the average value after eliminating abnormal numbers with the Grubbs method [34].

For concrete without admixtures (A1-A5), both increasing water and gas permeability coefficients with $\mathrm{w} / \mathrm{b}$ ratio can be observed in Figure 6, suggesting that w/b ratio has a strong influence on water and gas permeability. Moreover, to investigate the effect of admixture on permeability, concretes A6-A9 were used to compare with A3. It can be observed that adding admixtures into concrete (except A9, concrete with basalt fiber), the permeability can be reduced obviously. Among them, silica fume (A8) has the most significant reduction effect, which is similar to the conclusions of Ismail et al. [35] and Badogiannis et al. [36]. The decreasing effect of admixtures on these three permeability coefficients in descending order is A8 $>$ A7 $>$ A6. The reasons for the effect of admixtures on permeability can be attributed to the following. First, the incorporation of fibers into concrete increases microcracks, leading to the increased water and gas permeability coefficients, when compared with ordinary concrete. Second, the secondary hydration of concrete with silica fume can be completed in a relatively short time, which is more rapid than fly ash concrete; that is, fly ash concrete is still premature at the age of $28 \mathrm{~d}$. Therefore, the effect of silica fume on reducing the permeability coefficient is more obvious than that of fly ash.

In addition, the change effects of admixture on water and gas permeability coefficient are different, as shown in Table 5. In Table 5, minus and plus represents a decrease and increase when compared with A3, respectively.

As shown in Table 5, for the same admixture, the effect of admixture on water permeability coefficient is the most significant. Taking A6 for example, the relative reduction rate of permeability coefficient is $K_{w}(15.3 \%)>K_{g}(9.0 \%)>{ }_{D}$ $(2.2 \%)$. A similar trend can be found in concrete with other 
TABLE 4: CPMG parameters used in test.

\begin{tabular}{|c|c|c|c|c|c|c|c|c|c|c|c|c|}
\hline Parameters & Sf $(\mathrm{MHz})$ & $\mathrm{O} 1(\mathrm{~Hz})$ & $\mathrm{P} 1(\mu \mathrm{s})$ & $\mathrm{P} 2(\mu \mathrm{s})$ & $\mathrm{SW}(\mathrm{kHz})$ & TW (ms) & RG1 (db) & DRG1 & PRG & NS & $\mathrm{TE}(\mathrm{ms})$ & $\mathrm{NECH}$ \\
\hline Value & 23 & 403330 & 13 & 26 & 250 & 3000 & 10 & 3 & 1 & 64 & 0.2 & 16000 \\
\hline
\end{tabular}

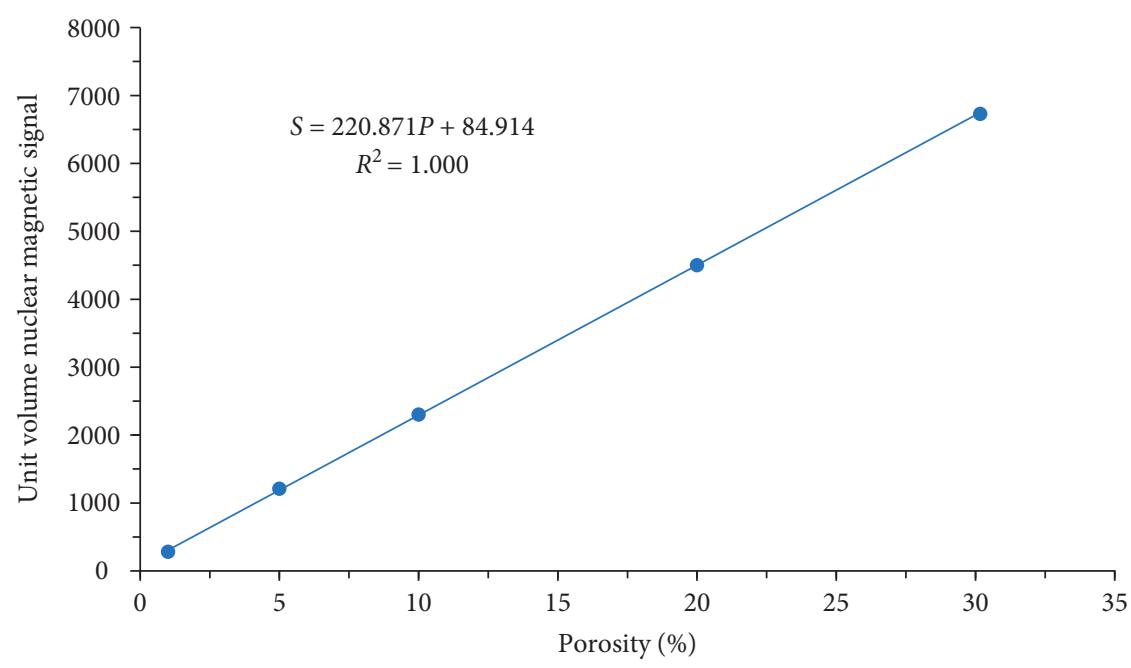

Figure 5: Calibration curve of NMR.

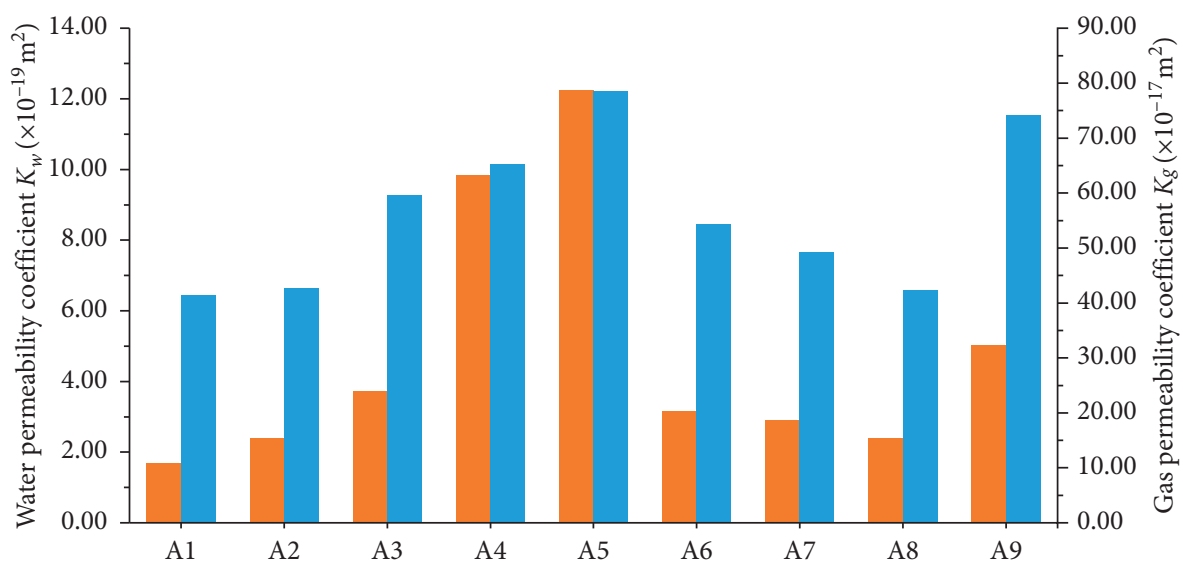

- Water permeability coefficient

- Gas permeability coefficient

Figure 6: Water and gas permeability coefficient of concrete (28d).

TABLE 5: Change rates of permeability when comparing A3 with concrete with admixtures.

\begin{tabular}{lcc}
\hline Number & Change rate of $K_{w}(\%)$ & Change rate of $K_{g}(\%)$ \\
\hline A6 & -15.3 & -9.0 \\
A7 & -22.0 & -17.3 \\
A8 & -10.5 & -6.2 \\
A9 & -35.9 & -17.4 \\
A10 & +26.0 & +24.3 \\
\hline
\end{tabular}

admixtures. Therefore, it can be concluded that different pore structures are formed when adding different admixtures in concrete, resulting in the different permeability.
4.2. Correlation between Water (Gas) Permeability and Microstructure Parameters. Generally, concrete with good chloride impermeability has superior water and gas impermeability. However, since the mechanisms of water and gas permeability are different, depending on the microstructure of concrete $[37,38]$, it is necessary to explore the correlation between water and gas permeability $[9,39]$. The correlation between water and gas permeability is shown in Figure 7. It can be found from Figure 7 that gas and water permeability coefficient both increase proportionally with w/ $\mathrm{b}$ ratio. A good correlation between water and gas permeability, with $R^{2}$ of 0.918 , can be obtained.

Table 6 shows the porosity of the test concrete measured by NMR [24]. 


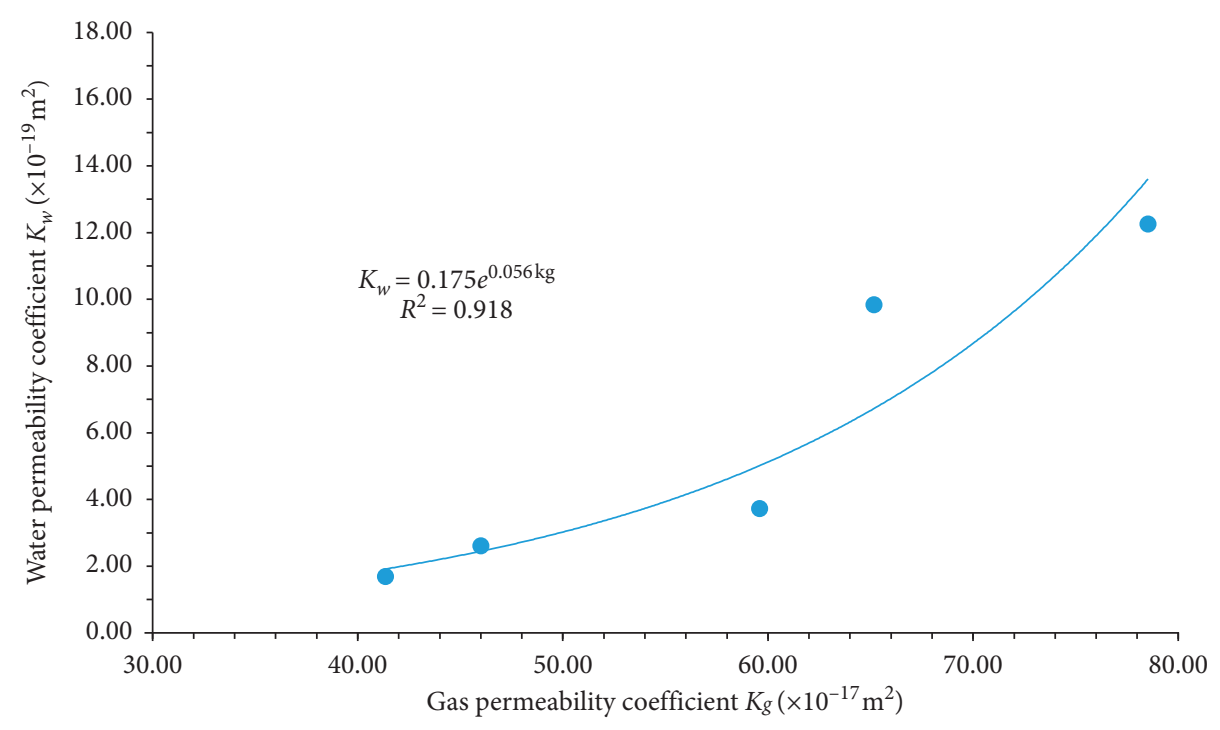

FIGURE 7: Water permeability coefficient versus gas permeability coefficient of concrete.

TABLe 6: Porosity of test concrete (\%).

\begin{tabular}{ccccccccc}
\hline A1 & A2 & A3 & A4 & A5 & A6 & A7 & A8 & A9 \\
\hline 9.36 & 9.54 & 9.97 & 13.05 & 15.46 & 9.45 & 9.10 & 8.73 & 14.72 \\
\hline
\end{tabular}

Previous research has indicated that, according to the pore diameter $(d)$, pores can be classified into gel pores $(<10 \mathrm{~nm})$, medium capillary pores $(10-100 \mathrm{~nm})$, large capillary pores $(100-1000 \mathrm{~nm})$, and air voids $(>1000 \mathrm{~nm})$ $[40,41]$. The pore size distribution of the test concrete measured by the NMR method is described in [24].

Actually, even with the same porosity, different pore size distributions may lead to different permeability. In addition, the size of media also has an influence on the transfer property in concrete. Thus, it is essential to consider the effects of pore size and porosity simultaneously on permeability. Zhang et al. [21] has defined an indicator-contributive porosity, that is, multiplying the porosity by the related pore size percentage in total porosity, which reflects the proportion of pore volume in a certain pore size range to the total volume of sample, to describe the combined effects of pore size and porosity on water and gas permeability. Figure 8 shows the contributive porosity within different ranges of pore size in concrete.

From Figure 8, it can be seen that the contributive porosity of large pore (100-1000 $\mathrm{nm}$ ) increases with $\mathrm{w} / \mathrm{b}$ ratio, leading to an increasing permeability. In addition, except basalt fiber (A9), adding admixtures into concrete can reduce porosity and contributive porosity of large pore significantly, making concrete more impermeable. Then, according to the contributive porosity determined in Figure 8 and the permeability given in Figure 6 , the correlation between contributive porosity within different ranges of pore size and permeability as well as diffusivity can be determined. Table 7 shows the corresponding correlation coefficients $R^{2}$.

From Table 7, it can be seen that the correlation between water permeability and contributive porosity for each pore diameter is always better than that of gas permeability, whether admixtures are adding or not. This may be attributed to the Klinkenberg effect. When the pore size is compared to the mean free path of the gas molecules, the gas flow at the pore walls will have a slip effect, which increases the gas flow rate. Eventually, the gas permeability is larger than the intrinsic (water) permeability [6]. Besides, better correlations between water permeability and segmental contributive porosity ranging from 10 to $100 \mathrm{~nm}$ and 100 to $1000 \mathrm{~nm}$ can be observed, but the gas permeability is more relevant to the segmental contributive porosity ranged from $100-1000 \mathrm{~nm}$. It is known that $\mathrm{N}_{2}$ has a smaller molecule with a dynamic size of $0.364 \mathrm{~nm}$ [42], and the diameter of water molecules is $0.22 \mathrm{~nm}$ [43]. Thus, $\mathrm{N}_{2}$ and water molecules can pass through the small capillary pores easily. Moreover, $\mathrm{N}_{2}$ and water molecules can pass through pores easily when the increasing quantity of pore diameter is 100-1000 nm.

There is a vital influence of admixtures on the relationship between permeability and pore size distribution of concrete $[44,45]$. Adding admixtures will cause a change of interface between cement paste and aggregate and the structure and morphology of pores. Part of connected pores may be blocked to be unconnected pores or expanded to be cracks $[46,47]$. From Table 7 , it can be seen that after adding admixtures, the correlation between contributive porosity of each pore size range with water permeability as well as gas permeability is reduced to a certain degree. This is because after adding admixtures, the porosity of concrete decreased; meanwhile, the pore size distribution of macropores and micropores decreased and increased, respectively.

4.3. Analysis of Differences between Water and Gas Permeability Coefficients. Figure 9 shows the change of the ratio of water and gas permeability coefficients $\left(K_{g} / K_{w}\right)$ with w/b ratio.

It can be seen that $\left(K_{g} / K_{w}\right)$ decreases gradually with the increase of $w / b$ ratio. Moreover, the slope tends to be sharp 


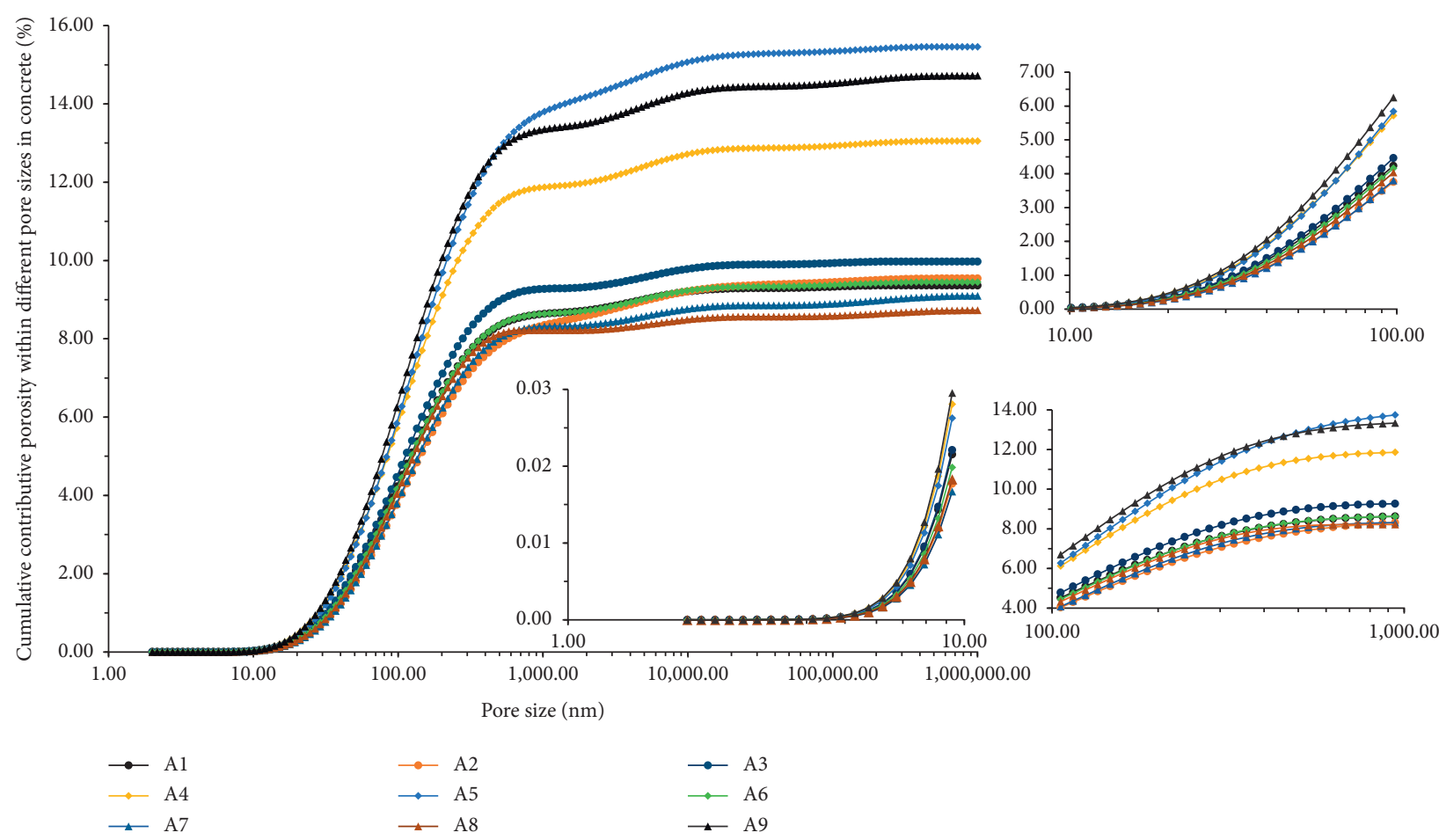

Figure 8: Cumulative contributive porosity within different pore size in concrete.

TABLE 7: $R^{2}$ of permeability and contributive porosity within different ranges of pore diameter in concrete.

\begin{tabular}{lccccc}
\hline & & $<10 \mathrm{~nm}$ & $10 \mathrm{~nm} \sim 100 \mathrm{~nm}$ & $100 \mathrm{~nm} \sim 1000 \mathrm{~nm}$ & $>1000 \mathrm{~nm}$ \\
\hline \multirow{2}{*}{ Different water-binder ratios } & Water permeability & 0.787 & 0.978 & 0.999 & 0.639 \\
& Gas permeability & 0.595 & 0.793 & 0.901 & 0.596 \\
\hline \multirow{2}{*}{ Different admixtures } & Water permeability & 0.913 & 0.889 & 0.984 & 0.837 \\
& Gas permeability & 0.882 & 0.853 & 0.967 & 0.827 \\
\hline
\end{tabular}

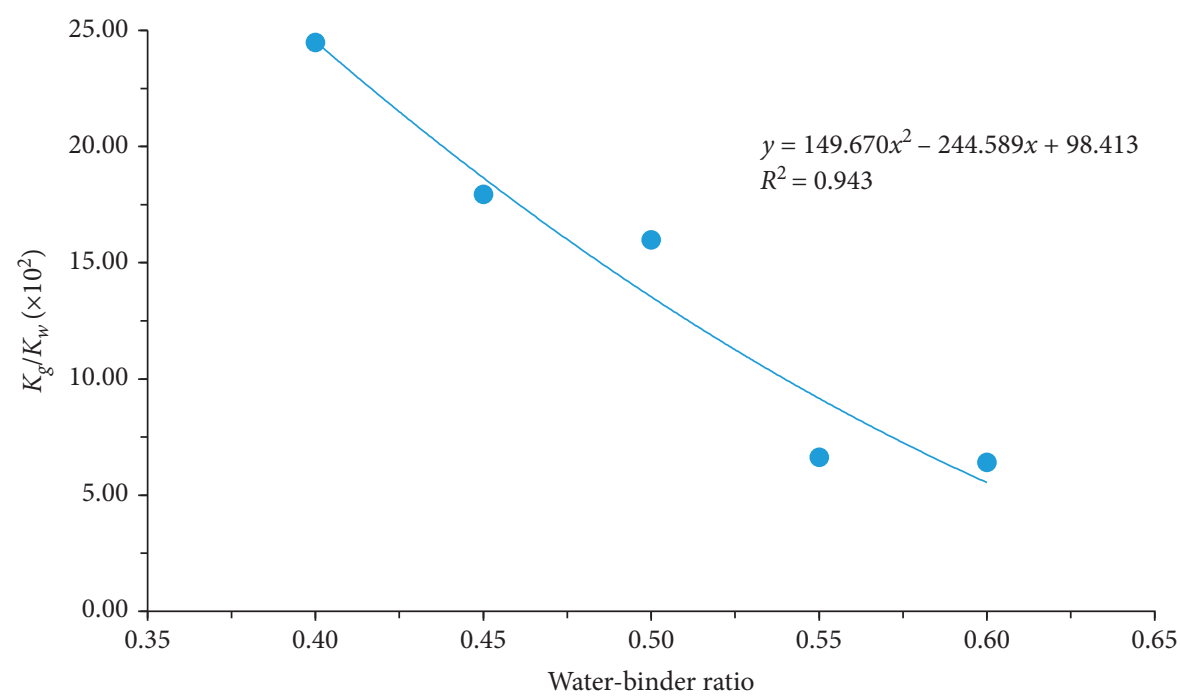

Figure 9: $\left(K_{g} / K_{w}\right)$ versus water-binder ratio of concrete.

when $w / b$ ratio is higher than 0.50 . In addition, admixture also has an influence on $\left(K_{g} / K_{w}\right)$. Figure 10 shows the change of $\left(K_{g} / K_{w}\right)$ with admixtures.
In Figure 10, A8 has the least permeability, and the permeability of A9 is the largest. Thus, it can be observed from Figure 10 that $\left(K_{g} / K_{w}\right)$ decreases with the increase of 


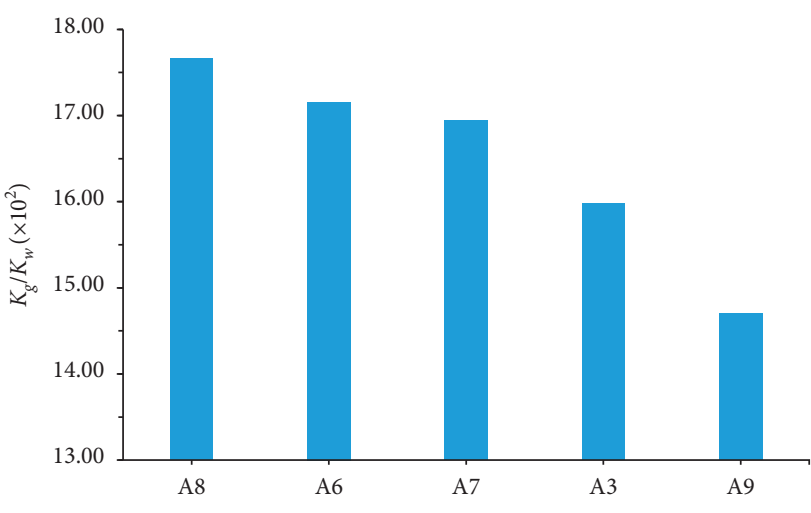

Figure 10: $\left(K_{g} / K_{w}\right)$ of concrete with different admixtures.

permeability. Moreover, the decrease degree of $\left(K_{g} / K_{w}\right)$ is positively related to permeability. Additionally, it can be observed that water permeability coefficient of concrete with admixtures is one or two orders of magnitude lower than the gas permeability coefficient, which may be related to the Klinkenberg effect [7, 8, 48].

It is found that, in the water permeability test, the time required to reach a steady seepage state is much longer than that in the gas permeability test. Besides, a continuous decrease in the injected water flow rate can be identified when conducting the water permeability test. These phenomena can be attributed to the following main reasons. First, when pure water is injected into pores, the chemical equilibrium of various phases presented in concrete will be disrupted, leading to a dissolution or precipitation phenomena of microcomponents in concrete. The rate of dissolution or precipitation is intrinsically much faster than the transport rate of water [9]. Moreover, the effective diameter of pores is progressively reduced with water penetration in the sample due to the expansion of cement-based materials caused by the capillary adsorption of water [10, 49], which may be a reason causing a smaller water permeability coefficient. This phenomenon is quite similar to the self-healing of cracks under water penetration [50].

\section{Conclusions}

The conclusions of this work can be summarized as follows:

(1) There is an obvious effective mutual relationship between water and gas permeability of concrete. Water permeability coefficient is one or two orders of magnitude lower than gas permeability coefficient of the test concrete. The difference between water and gas permeability coefficient increases with the decreasing of concrete permeability. Water and gas permeability coefficient of concrete both increase with w/b ratio, which can be considered as a main factor affecting the impermeability of concrete. The variations of water and gas permeability coefficient of concrete with admixtures are similar, but the effects of the same admixture on water and gas permeability of concrete are different, in which water permeability coefficient is most dependent on the addition of admixtures.

(2) Relationship between microstructure and water permeability is different from that and gas permeability. Better correlations between water permeability and segmental contributive porosity ranging from 10 to $100 \mathrm{~nm}$ and 100 to $1000 \mathrm{~nm}$ can be observed, but the gas permeability is more relevant to the segmental contributive porosity ranging from 100 to $1000 \mathrm{~nm}$. Moreover, the correlation of water permeability with contributive porosity for each pore diameter is always better than that of gas permeability. Besides, the addition of admixtures has a great effect on the relationship between macroscopic permeability and pore size distribution.

\section{Data Availability}

The experiment is a series of experiments completed by the author together with Fang Zhaofeng and Bianfan. The data in the manuscript comes from this experiment.

\section{Conflicts of Interest}

The authors declare that they have no conflicts of interest.

\section{Acknowledgments}

The authors acknowledge and appreciate support received from the Research Fund for the Natural Science Foundation of Zhejiang Province (LQ18G010007, to Yurong Zhang; LY17E090007 and LY13E090008, to Junzhi Zhang) and National Natural Science Foundation of China (50879079 and 51279181, to Junzhi Zhang). Moreover, thanks are due to Jiandong Wang, Chuanqing Fu, and Fan Bian for their assistance during the experiments.

\section{References}

[1] N. Banthia, A. Biparva, and S. Mindess, "Permeability of concrete under stress," Cement and Concrete Research, vol. 35, no. 9, pp. 1651-1655, 2005.

[2] L. J. Klinkenberg, "The permeability of porous media to liquids and gases," Drilling and Production Practice, vol. 2, no. 2, pp. 200-213, 1941.

[3] K. Maekawa, R. Chaube, and T. Kishi, Modelling of Concrete Performance: Hydration, Microstructure and Mass Transport, Spon Press, London, UK, 1st edition, 1999.

[4] P. V. Chavan and K. E. Dennett, "Wetland simulation model for nitrogen, phosphorus, and sediments retention in constructed wetlands," Water, Air, and Soil Pollution, vol. 187, no. 1, pp. 109-118, 2008.

[5] G. W. Scherer, J. J. Valenza, and G. Simmons, "New methods to measure liquid permeability in porous materials," Cement and Concrete Research, vol. 37, no. 3, pp. 386-397, 2007.

[6] L. Anez, S. Calas-Etienne, J. Primera, and T. Woignier, "Gas and liquid permeability in nano composites gels: comparison of Knudsen and Klinkenberg correction factors," Microporous and Mesoporous Materials, vol. 200, pp. 79-85, 2014. 
[7] P. B. Bamforth, "The relationship between permeability coefficients for concrete obtained using liquid and gas," Magazine of Concrete Research, vol. 39, no. 138, pp. 3-11, 1987.

[8] Z. A. Kameche, F. Ghomari, M. Choinska, and A. Khelidj, "Assessment of liquid water and gas permeabilities of partially saturated ordinary concrete," Construction and Building Materials, vol. 65, no. 13, pp. 551-565, 2014.

[9] F. Skoczylas and J. P. Henry, "A study of the intrinsic permeability of granite to gas," International Journal of Rock Mechanics and Mining Sciences \& Geomechanics Abstracts, vol. 32, no. 2, pp. 171-179, 1995.

[10] J. Marchand, "Modeling the behavior of unsaturated cement systems exposed to aggressive chemical environments," Materials and Structures, vol. 34, no. 4, pp. 195-200, 2001.

[11] C. Arya and J. B. Newman, "An assessment of four methods of determining the free chloride content of concrete," Materials and Structures, vol. 23, no. 5, pp. 319-330, 1990.

[12] M. Zalzale, P. J. Mcdonald, and K. L. Scrivener, “A 3D lattice Boltzmann effective media study: understanding the role of C-S-H and water saturation on the permeability of cement paste," Modelling and Simulation in Materials Science and Engineering, vol. 21, no. 8, pp. 1-16, 2013.

[13] Z. Yu, C. Ni, M. Tang, and X. Shen, "Relationship between water permeability and pore structure of Portland cement paste blended with fly ash," Construction and Building Materials, vol. 175, pp. 458-466, 2018.

[14] H. Ma, D. Hou, and Z. Li, "Two-scale modeling of transport properties of cement paste: formation factor, electrical conductivity and chloride diffusivity," Computational Materials Science, vol. 110, pp. 270-280, 2015.

[15] J. J. Chen, A. K. H. Kwan, and Y. Jiang, "Adding limestone fines as cement paste replacement to reduce water permeability and sorptivity of concrete," Construction and Building Materials, vol. 56, no. 4, pp. 87-93, 2014.

[16] Y. Pei, F. Agostini, and F. Skoczylas, "The effects of high temperature heating on the gas permeability and porosity of a cementitious material," Cement and Concrete Research, vol. 95, pp. 141-151, 2017.

[17] T. Sinsiri, P. Chindaprasirt, and C. Jaturapitakkul, "Influence of fly ash fineness and shape on the porosity and permeability of blended cement pastes," International Journal of Minerals, Metallurgy, and Materials, vol. 17, no. 6, pp. 683-690, 2010.

[18] S. Tsivilis, E. Chaniotakis, G. Batis et al., "The effect of clinker and limestone quality on the gas permeability, water absorption and pore structure of limestone cement concrete," Cement and Concrete Composites, vol. 21, no. 2, pp. 139-146, 1999.

[19] M. Zuena, P. Tomasin, M. F. Alberghina et al., "Comparison between mercury intrusion porosimetry and nuclear magnetic resonance relaxometry to study the pore size distribution of limestones treated with a new consolidation product," Measurement, vol. 143, pp. 234-245, 2019.

[20] Y. Ji, Z. Sun, X. Yang, C. Li, and X. Tang, "Assessment and mechanism study of bleeding process in cement paste by ${ }^{1} \mathrm{H}$ low-field NMR," Construction and Building Materials, vol. 100, pp. 255-261, 2015.

[21] J. Zhang, J. Guo, D. Li, Y. Zhang, F. Bian, and Z. Fang, "The influence of admixture on chloride time-varying diffusivity and microstructure of concrete by low-field NMR," Ocean Engineering, vol. 142, pp. 94-101, 2017.

[22] M. Tziotziou, E. Karakosta, I. Karatasios et al., "Application of ${ }^{1} \mathrm{H}$ NMR to hydration and porosity studies of lime-pozzolan mixtures," Microporous and Mesoporous Materials, vol. 139, no. 1-3, pp. 16-24, 2011.
[23] C. Zhou, F. Ren, Q. Zeng, L. Xiao, and W. Wang, "Pore-size resolved water vapor adsorption kinetics of white cement mortars as viewed from proton NMR relaxation," Cement and Concrete Research, vol. 105, pp. 31-43, 2018.

[24] J. Zhang, F. Bian, Y. Zhang, Z. Fang, C. Fu, and J. Guo, "Effect of pore structures on gas permeability and chloride diffusivity of concrete," Construction and Building Materials, vol. 163, pp. 402-413, 2018.

[25] J. J. Kollek, "The determination of the permeability of concrete to oxygen by the Cembureau method-a recommendation," Materials and Structures, vol. 22, no. 3, pp. 225-230, 1989.

[26] RILEM Technical Committees, "Test for gas permeability of concrete," Materials and Structures, vol. 32, no. 3, pp. 176$178,1999$.

[27] H. Loosveldt, Z. Lafhaj, and F. Skoczylas, "Experimental study of gas and liquid permeability of a mortar," Cement and Concrete Research, vol. 32, no. 9, pp. 1357-1363, 2002.

[28] S. Care and F. Derkx, "Determination of relevant parameters influencing gas permeability of mortars," Construction and Building Materials, vol. 25, no. 3, pp. 1248-1256, 2011.

[29] R. P. Khatri and V. Sirivivatnanon, "Methods for the determination of water permeability of concrete," ACI Materials Journal, vol. 94, no. 3, pp. 257-261, 1997.

[30] V. Boel, K. Audenaert, and G. De Schutter, "Gas permeability and capillary porosity of self-compacting concrete," Materials and Structures, vol. 41, no. 7, pp. 1283-1290, 2008.

[31] P. F. Faure and S. Rodts, "Proton NMR relaxation as a probe for setting cement pastes," Magnetic Resonance Imaging, vol. 26, no. 8, pp. 1183-1196, 2008.

[32] Z. Zhang, B. Zhang, and P. Yan, "Hydration and microstructures of concrete containing raw or densified silica fume at different curing temperatures," Construction and Building Materials, vol. 121, pp. 483-490, 2016.

[33] J.-P. Korb, "NMR and nuclear spin relaxation of cement and concrete materials," Current Opinion in Colloid \& Interface Science, vol. 14, no. 3, pp. 192-202, 2009.

[34] H. Peyre, A. Leplège, and J. Coste, "Missing data methods for dealing with missing items in quality of life questionnaires. A comparison by simulation of personal mean score, full information maximum likelihood, multiple imputation, and hot deck techniques applied to the SF-36 in the French 2003 decennial health survey," Quality of Life Research, vol. 20, no. 2, pp. 287-300, 2011.

[35] I. Ismail, S. A. Bernal, J. L. Provis et al., "Influence of fly ash on the water and chloride permeability of alkali-activated slag mortars and concretes," Construction and Building Materials, vol. 48, no. 11, pp. 1187-1201, 2013.

[36] E. Badogiannis, E. Aggeli, V. G. Papadakis, and S. Tsivilis, "Evaluation of chloride-penetration resistance of metakaolin concrete by means of a diffusion-binding model and of the $k$ value concept," Cement and Concrete Composites, vol. 63, no. 2, pp. 1-7, 2015.

[37] M. L. Berndt, "Properties of sustainable concrete containing fly ash, slag and recycled concrete aggregate," Construction and Building Materials, vol. 23, no. 7, pp. 2606-2613, 2009.

[38] T. Sugiyama, T. W. Bremner, and Y. Tsuji, "Determination of chloride diffusion coefficient and gas permeability of concrete and their relationship," Cement and Concrete Research, vol. 26, no. 5, pp. 781-790, 1996.

[39] S. Real and J. A. Bogas, "Oxygen permeability of structural lightweight aggregate concrete," Construction and Building Materials, vol. 137, pp. 21-34, 2017.

[40] J. Liu, G. Ou, Q. Qiu, X. Chen, J. Hong, and F. Xing, "Chloride transport and microstructure of concrete with/without fly ash 
under atmospheric chloride condition," Construction and Building Materials, vol. 146, pp. 493-501, 2017.

[41] Y. Yokoyama, T. Yokoi, and J.-i. Ihara, "The effects of pore size distribution and working techniques on the absorption and water content of concrete floor slab surfaces," Construction and Building Materials, vol. 50, no. 1, pp. 560-566, 2014.

[42] C. Sun and B. Bai, "Diffusion of gas molecules on multilayer graphene surfaces: dependence on the number of graphene layers," Applied Thermal Engineering, vol. 116, pp. 724-730, 2017.

[43] H. Naono, M. Shimoda, N. Morita, M. Hakuman, K. Nakai, and S. Kondo, "Interaction of water molecules with nongraphitized and graphitized carbon black surfaces†," Langmuir, vol. 13, no. 5, pp. 1297-1302, 1997.

[44] Z. Wu, C. Shi, and K. H. Khayat, "Influence of silica fume content on microstructure development and bond to steel fiber in ultra-high strength cement-based materials (UHSC)," Cement and Concrete Composites, vol. 71, pp. 97-109, 2016.

[45] S.-c. Kou, C.-s. Poon, and F. Agrela, "Comparisons of natural and recycled aggregate concretes prepared with the addition of different mineral admixtures," Cement and Concrete Composites, vol. 33, no. 8, pp. 788-795, 2011.

[46] J. B. Camacho, S. M. Abdelkader, E. R. Pozo, and A. M. Terrades, "The influence of ion chloride on concretes made with sulfate-resistant cements and mineral admixtures," Construction and Building Materials, vol. 70, pp. 483-493, 2014.

[47] M. K. Mohammed, A. R. Dawson, and N. H. Thom, "Macro/ micro-pore structure characteristics and the chloride penetration of self-compacting concrete incorporating different types of filler and mineral admixture," Construction and Building Materials, vol. 72, pp. 83-93, 2014.

[48] K. B. Batchelor, "An electrical conductivity method for measuring the effects of additives on effective diffusivities in portland cement pastes," Cement and Concrete Research, vol. 24, no. 4, pp. 752-764, 1994.

[49] H. W. Reinhardt, "Penetration and permeability of concretebarriers to organic and contaminating liquids," RILEM report 16, Spon Press, London, UK, 1997.

[50] C. Edvardsen, "Water permeability and autogenous healing of cracks in concrete," ACI Materials Journal, vol. 96, no. 4, pp. $448-454,1999$. 